\title{
Resposta do pinhão-manso à aplicação de níveis de irrigação e doses de adubação potássica ${ }^{1}$
}

Ednaldo L. Oliveira ${ }^{2}$, Manoel A. Faria ${ }^{3}$, Adão W. P. Evangelista ${ }^{4}$ \& Paulo C. Melo ${ }^{5}$

\section{RESUMO}

O cultivo do pinhão-manso vem despertando grande interesse para a produção de biodiesel. Apesar da irrigação e da adubação contribuírem para o aumento da sua produção, poucas pesquisas têm sido realizadas neste contexto. Assim, o objetivo deste trabalho foi avaliar o crescimento e a produtividade de sementes de pinhão-manso em resposta a diferentes doses de adubação potássica e lâminas de irrigação. O experimento foi conduzido na Universidade Federal de Lavras (UFLA), na região sul do estado de Minas Gerais. Os tratamentos foram constituídos de quatro lâminas de irrigação calculadas com base em percentagens da evaporação do tanque Classe A (ECA), ou seja, 0, 40, 80 e $120 \%$ e quatro doses de adubação potássica $\left(30,60,90\right.$ e $120 \mathrm{~kg} \mathrm{ha}^{-1}$ de $\left.\mathrm{K}_{2} \mathrm{O}\right)$. Para avaliar o crescimento e a produtividade de sementes do pinhão-manso utilizaram-se dados do primeiro e do segundo ano de cultivo. A irrigação produziu efeitos significativos sobre o crescimento e produtividade de sementes de pinhão-manso; entretanto, as doses de adubação potássica aplicadas não influenciaram as fontes de variação analisadas.

Palavras-chave: Jatropha curcas, biocombustíveis, manejo de água, nutrição mineral

\section{Response of Jatropha curcas crop to irrigation and potassium fertilization levels}

\begin{abstract}
Jatropha curcas crop is raising attention as an alternative crop for biodiesel production. Despite the irrigation and mineral fertilization to promote increase of Jatropha curcas yield, few studies have been conducted on this issue. The purpose of this work was to evaluate the growth and productivity of Jatropha curcas, in response to irrigation management and potassium fertilization doses. The field experiment was carried out at the Federal University of Lavras in the southern part of the State of Minas Gerais. Four different irrigation depths, corresponding to different fractions $(0,40,80,120 \%)$ of the Class A pan evaporation (ECA), and four potassium doses $\left(30,60,90\right.$ and $120 \mathrm{~kg} \mathrm{ha}^{-1}$ of $\mathrm{K}_{2} \mathrm{O}$ ) were used as treatments. To evaluate the growth and yield of Jatropha curcas seeds the data corresponding to first and second year of cultivation was used. The results showed that plants irrigated showed better productivity and initial growth, while potassium fertilization levels did not show significant effect.
\end{abstract}

Key words: biofuels, water management, mineral nutrition

\footnotetext{
Projeto financiado pela Fundação de Amparo à Pesquisa do Estado de Minas Gerais - FAPEMIG

IFNMG, Campus Araçuaí, Fazenda do Meio Pé s/n, BR 367, km 278, CEP 39600-000, Araçuaí, MG. E-mail: ednaldoliberato@yahoo.com.br

3 DEG/UFLA, Campus Universitário, CP 3037, CEP 37200-000, Lavras, MG. Fone: (35) 3829 1390. E-mail: mafaria@deg.ufla.br

${ }^{4}$ EA/UFG, Rodovia Goiânia/Nova Veneza, Km 0, CEP 74690-900, Goiânia, GO. Fone: (62) 3521 1534. E-mail: awpego@bol.com.br

DAG/UFLA, Fone: (35) 3829 1333. E-mail: pcmelo@dag.ufla.br
} 


\section{INTRODUÇÃO}

Embora se trate de uma planta conhecida e cultivada na América desde tempos remotos e disseminada por todas as áreas tropicais e algumas áreas temperadas, o pinhão-manso (Jatropha curcas L.) ainda se encontra em processo de domesticação. Somente nas últimas três décadas passou a ser estudado agronomicamente (Saturnino et al., 2005).

Após a crise do petróleo, na década de 70, estudos com combustíveis alternativos aos derivados do petróleo foram intensificados. A cultura do pinhão-manso surgiu como boa alternativa como fornecedora de matéria-prima para produção de biodiesel e bioquerosene, por se tratar de planta originária do continente sul-americano, ser perene e produtora de sementes ricas em óleo de fácil colheita e com propriedades capazes de produzir combustível de alta qualidade, razão por que se torna competitivo internacionalmente de vez que suas características também superam o padrão de qualidade do óleo de colza comercializado, hoje, na Europa (Dabdoub et al., 2009).

O pinhão-manso é considerado uma cultura rústica, adaptado às mais diversas condições edafoclimáticas, que sobrevive em condições de solos marginais de baixa fertilidade natural (Arruda et al., 2004). Contudo, para se obter alta produtividade de sementes em plantio comercial a planta necessita de água e exige solos férteis e com boas condições físicas. Logo, a irrigação e a correção da acidez e da fertilidade do solo são fatores decisivos para se obter sucesso e lucratividade com a cultura.

A recomendação de adubação de uma cultura depende das demandas nutricionais das plantas para o crescimento vegetativo e reprodutivo (Laviola et al., 2007). Também devem ser levadas em consideração a eficiência de aproveitamento dos adubos aplicados e a fração de nutrientes suprida pelo solo (Prezotti, 2001).

Dentre os nutrientes o potássio é o segundo mineral requerido em maior quantidade pelas espécies vegetais, depois do nitrogênio, e tem alta mobilidade na planta, em qualquer concentração, seja dentro da célula, no tecido vegetal, no xilema ou no floema. Saturnino et al. (2005) observaram, em plantas de pinhão-manso, que o potássio foi o mineral encontrado em maior concentração em comparação com os demais macronutrientes sinalizando, portanto, que o potássio pode ser um dos nutrientes exigidos em maior quantidade, por esta cultura. Segundo Malavolta et al. (1997), na maioria das culturas com alto potencial produtivo o teor de potássio excede o de nitrogênio por participar de diversas fases do metabolismo das plantas, como o controle de turgidez dos tecidos, síntese de carboidratos e proteínas, respiração e regulação da abertura e fechamento dos estômatos.

Laviola \& Dias (2008) verificaram, em folhas de pinhãomanso, uma relação N/K de 2,3 e nos frutos de 1,4, indicando que na fase em que a planta entra em produção ocorre aumento do seu requerimento por potássio, possivelmente por este nutriente exercer papel relevante na formação dos frutos, atuando no transporte de fotoassimilados.

Além de uma adubação correta, o fornecimento de água para a cultura de forma eficiente interfere diretamente no processo de produção agrícola. São cada vez mais frequentes os problemas climáticos, como a estiagem, que atinge severamente as culturas não irrigadas, mesmo em regiões climaticamente aptas para a maioria das culturas, como o sul do estado de Minas Gerais, que apresenta períodos de veranico dentro da estação chuvosa, caso em que a irrigação é uma técnica que, além de incrementar a produtividade, pode proporcionar a obtenção de um produto diferenciado e de melhor qualidade, com bom preço de mercado. No sul de Minas Gerais vários pesquisadores constataram um aumento significativo da produtividade de diversas culturas irrigadas, quando comparada com os cultivos de sequeiro (Amorim et al., 2005; Custódio et al., 2007; Sato et al., 2007; Silva et al., 2008).

A produtividade do pinhão-manso é muito variável, dependendo da região, do método de cultivo e dos tratos culturais, da regularidade pluviométrica e da fertilidade do solo. Segundo Brasil (2009), a produção anual de sementes em plantio com espaçamento de 3,0 x 3,0 m, pode atingir de 3,0 a 4,0 $\mathrm{t} \mathrm{ha}^{-1}$, ou até mais, à mercê do sistema de cultivo. Entretanto, Carnielli (2003) afirma que o pinhão-manso carece de três a quatro anos para atingir a idade produtiva, que se estende por 40 anos e produz, no mínimo, duas toneladas de óleo por hectare.

Numa área de baixada irrigada com boa fertilidade, Purcino \& Drumond (1986) observaram que o pinhão-manso começou a produzir no segundo ano atingindo $2000 \mathrm{~kg} \mathrm{ha}^{-1}$ de sementes. Por outro lado, Drumond et al. (2007) obtiveram produtividades variando de $330 \mathrm{~kg} \mathrm{ha}^{-1}$ em condições de sequeiro,a $1200 \mathrm{~kg} \mathrm{ha}^{-1}$ em área irrigada, já no primeiro ano de cultivo, em Petrolina, PE.

Ante o exposto, o objetivo deste trabalho foi avaliar o crescimento e a produtividade do pinhão-manso submetido a diferentes níveis de irrigação e doses de adubação potássica na região sul do estado de Minas Gerais.

\section{Material e MÉTODOS}

O experimento foi desenvolvido no setor de Fruticultura do Departamento de Agricultura da Universidade Federal de Lavras (UFLA) em latitude de $21^{\circ} 13$ ' $50^{\prime \prime} \mathrm{S}$, longitude de $44^{\circ} 58^{\prime}$ $55^{\prime \prime} \mathrm{W}$ e altitude de $902 \mathrm{~m}$ em clima subtropical úmido mesotérmico. O solo da área experimental foi classificado em Latossolo Vermelho Distroférrico (Tabela 1). A precipitação acumulada durante os dois anos de realização do experimento foi de 2665 mm enquanto a lâmina média de irrigação aplicada foi de $5000 \mathrm{~mm}$.

As mudas de pinhão-manso provenientes de sementes foram produzidas no setor de Cafeicultura do Departamento de Agricultura da Universidade Federal de Lavras, em Lavras, Minas Gerais. A semeadura foi realizada em tubetes de $120 \mathrm{~mL}$, utilizando-se substrato comercial, segundo as recomendações de Anez et al. (2005). As mudas foram transplantadas no espaçamento de $3,0 \times 1,5 \mathrm{~m}$.

O delineamento experimental utilizado foi o de blocos ao acaso, com quatro repetições. Os tratamentos corresponderam a quatro doses de adubação potássica e quatro níveis de irrigação. Os tratamentos de adubação foram: $\mathrm{T}_{0}=$ testemunha $\left(0 \mathrm{~kg} \mathrm{ha}^{-1}\right.$ de $\left.\mathrm{K}_{2} \mathrm{O}\right) ; \mathrm{T}_{1}=30 \mathrm{~kg} \mathrm{ha}^{-1}$ de $\mathrm{K}_{2} \mathrm{O} ; \mathrm{T}_{2}=60 \mathrm{~kg} \mathrm{ha}^{-1} \mathrm{de}$ 
Tabela 1. Características químicas do solo da área experimental, na camada de 0 a $0,20 \mathrm{~m}$ de profundidade

\begin{tabular}{|c|c|c|c|c|c|c|c|}
\hline \multirow{2}{*}{$\begin{array}{c}\text { MO } \\
\mathrm{g} \mathrm{kg}^{-1}\end{array}$} & \multirow{2}{*}{$\begin{array}{c}\mathrm{pH} \\
\left(\mathrm{H}_{2} \mathrm{O}\right)\end{array}$} & $\mathbf{P}$ & $\mathrm{K}$ & $\mathrm{Ca}^{2+}$ & $\mathrm{Mg}^{2+}$ & $\mathbf{A l}^{3+}$ & CTC \\
\hline & & \multicolumn{2}{|c|}{$\mathrm{mg} \mathrm{dm}^{-3}$} & \multicolumn{4}{|c|}{$\mathrm{cmol}_{\mathrm{c}} \mathrm{dm}^{-3}$} \\
\hline 2,1 & 6,5 & 6,8 & 101 & 4,0 & 0,9 & 0,0 & 7,1 \\
\hline \multirow{2}{*}{$\begin{array}{l}\mathbf{V} \\
\%\end{array}$} & $S$ & $\mathbf{P}_{\text {rem }}$ & $\mathrm{Zn}$ & $\mathrm{Fe}$ & $\mathrm{Mn}$ & $\mathrm{Cu}$ & B \\
\hline & \multicolumn{7}{|c|}{$\mathrm{mg} \mathrm{dm}^{-3}$} \\
\hline 73,1 & 22,7 & 13,6 & 3,6 & 18,2 & 20,3 & 24,6 & 0,4 \\
\hline
\end{tabular}

pH em $\mathrm{H}_{2} \mathrm{O}$ - relação 1:2,5. CTC - capacidade de troca de cátions. P, K, Fe, Zn, Mn, Cu - extrator Mehlich-1. $\mathrm{Ca}^{2+}, \mathrm{Mg}^{2+}, \mathrm{Al}^{3+}: \mathrm{KCl} 1 \mathrm{~mol} \mathrm{~L}^{-1} \cdot \mathrm{H}+\mathrm{AL}$ - método $\mathrm{Ca}(\mathrm{OAC})_{2} 0,5 \mathrm{~mol} \mathrm{~L}^{-1}, \mathrm{pH}$ 7. Matéria orgânica - C orgânico x 1,724 - Walkley Black

$\mathrm{K}_{2} \mathrm{O} ; \mathrm{T}_{3}=90 \mathrm{~kg} \mathrm{ha}^{-1}$ de $\mathrm{K}_{2} \mathrm{O}$; e $\mathrm{T}_{4}=120 \mathrm{~kg} \mathrm{ha}^{-1}$ de $\mathrm{K}_{2} \mathrm{O}$. As aplicações foram parceladas em três vezes, sendo a primeira no plantio definitivo e as demais em cobertura. A segunda aplicação foi realizada 30 dias após o transplantio (DAT) e a terceira aos 60 DAT. Os tratamentos de irrigação corresponderam a lâminas de água calculadas com base na porcentagem de evaporação acumulada do tanque Classe A (ECA), ou seja: $\mathrm{L}_{0}=$ sem irrigação; $\mathrm{L}_{40}=40 \%$ da ECA; $\mathrm{L}_{80}=80 \%$ da ECA e $\mathrm{L}_{120}=120 \%$ da ECA. O sistema de irrigação utilizado foi por gotejamento com emissores espaçados a cada $0,50 \mathrm{~m}$, com o qual as plantas foram irrigadas nas segundas, quartas e sextas-feiras. As parcelas experimentais foram constituídas de seis linhas de plantio de pinhão-manso, compostas de 48 plantas, em que 24 foram consideradas úteis. Aárea total ocupada pelo experimento foi de $3456 \mathrm{~m}^{2}$.

A adubação química no plantio com nitrogênio e fósforo foi realizada na mesma dosagem para todas as parcelas experimentais, com base nos resultados de análise de fertilidade do solo, tomando-se como fundamentação teórica as recomendações de adubação para a cultura da mamoneira, de acordo com Lange et al. (2005), por ser uma cultura da mesma família (Euforbiácea) do pinhão-manso, também produtora de sementes ricas em óleo. Tal procedimento foi adotado por não existir, até o momento, recomendações de adubação específicas para a cultura do pinhão-manso.

Após uma primeira avaliação de caracterização do experimento, antes do início da aplicação dos tratamentos, constatou-se que não havia diferenças significativas entre as parcelas partindo-se, então, de uma condição homogênea em que se considerou que todas as plantas apresentavam o mesmo desenvolvimento; a partir daí, acompanhou-se o crescimento da cultura.

Foram avaliados os seguintes parâmetros de crescimento da cultura: diâmetro de copa, altura de planta, diâmetro de caule e número de ramificações no ramo principal. A altura de planta foi medida a uma altura de $10 \mathrm{~cm}$ da superfície do solo e o diâmetro de copa foi medido no sentido perpendicular à linha de plantio e, finalmente, o número de ramificações no ramo principal foi avaliado através de contagem direta. Foram realizadas quatro avaliações nas seguintes épocas: 70, 120, 150 e 442 dias após o transplantio (DAT).

A colheita das parcelas foi feita de forma manual e, após a homogeneização dos frutos colhidos, as amostras foram acondicionadas em sacaria de fio plástico trançado e submetidas a secagem em bancadas de madeira suspensa ao ar livre até atingirem umidade na faixa de $7 \%$ com base em peso; em seguida, foram retirados $500 \mathrm{~g}$ de frutos da cultura para o beneficiamento e posteriormente se determinaram: o peso do pinhão-manso beneficiado, a umidade e a produtividade de sementes. Para avaliar a resposta da cultura utilizaram-se dados de produtividade de sementes referentes ao primeiro ano de produção, ou seja, entre o período de um e dois anos após o transplantio das mudas.

Os dados obtidos foram submetidos às análises de variância e de regressão polinomial, utilizando-se do software estatístico SISVAR (Lavras, MG). Quando os dados dos tratamentos apresentaram diferenças significativas pelo teste $\mathrm{F}$ a nível de 5\% de probabilidade, realizaram-se as análises de regressão. Os graus de liberdade dos tratamentos foram decompostos em componentes de regressão polinomial optando-se pelo modelo de mais alto grau significativo, para a construção das figuras.

\section{RESULTADOS E DISCUSSÃO}

Na Figura 1 se visualizam os valores de precipitação $(P)$ e evaporação do tanque Classe (ECA) para Lavras, ocorridos durante o período de realização do experimento (11/2006 a 10/ 2008), indicando haver concentração das precipitações na região entre os meses de novembro a março, cujos valores precipitados superam consideravelmente a ECA enquanto nos meses de abril a outubro a precipitação foi inferior à ECA, caracterizando-se déficit hídrico no período. Essas informações estão de acordo com Dantas et al. (2007), ao relatarem que a estação chuvosa para Lavras se estende de outubro a março e a seca compreende os meses de abril a setembro.

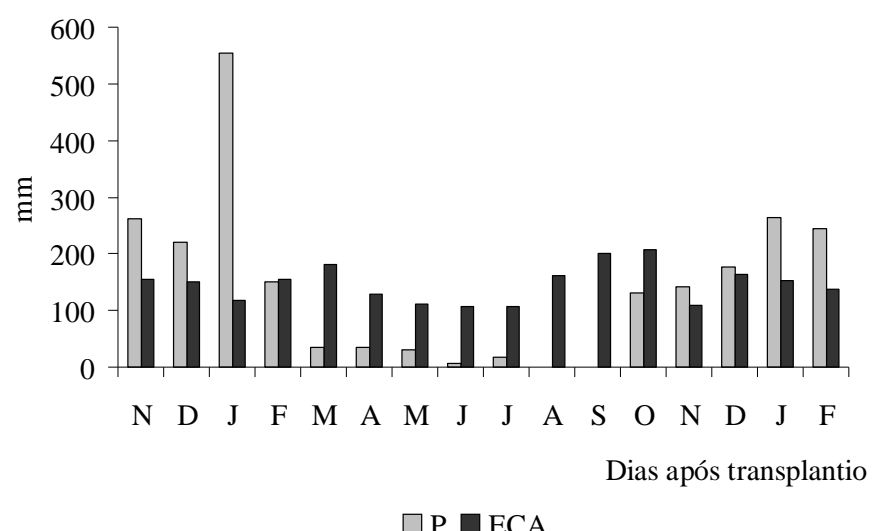

Figura 1. Totais mensais $(\mathrm{mm})$ para precipitação $(\mathrm{P})$ e evaporação do tanque Classe A (ECA) ocorridos no período de $11 / 2006$ a $10 / 2008$

O balanço entre a ECA e a precipitação mostra déficit hídrico na ordem de 949,53 e 552,27 mm, para os períodos de fevereiro a outubro de 2007 e abril a outubro de 2008 , respectivamente. Este déficit, por outro lado, é função da ausência ou dos baixos valores precipitados entre os meses de junho a setembro e de uma elevada demanda d'água pela atmosfera, o que pode ser constatado através dos valores da ECA, superiores a $5,0 \mathrm{~mm} \mathrm{~d}^{-1}$ (Figura 1). Ressalta-se que um déficit hídrico superior a $150 \mathrm{~mm}$ pode comprometer a produção da maioria das culturas. Com bases nesses dados pode-se justificar, então, a irrigação do 
pinhão-manso em Lavras, sul de Minas Gerais, mesmo essa região apresentando precipitação média acima de $1000 \mathrm{~mm}$ (Dantas et al., 2007), porém com ocorrência de seca prolongada dentro da estação chuvosa. Segundo Jiang \& Zhang (2002), a reduzida disponibilidade de água é um dos fatores ambientais mais importantes na regulação do crescimento, desenvolvimento e produtividade de sementes e óleo de plantas oleaginosas.

Verificou-se, ao longo do experimento, que quando se aplicaram as diferentes lâminas de irrigação e doses de adubação potássica a resposta da cultura foi semelhante, razão pela qual são apresentados somente os resultados referentes à ultima avaliação, ou seja, aos 442 DAT.

Os resultados da análise de variância dos dados das características da planta analisadas em função das lâminas de irrigação e doses de potássio no final de 14 meses de condução do experimento estão dispostos na Tabela 2. Observa-se que as características de crescimento da planta analisada não foram influenciadas pelas doses de adubação potássica aplicadas nem pela interação níveis de irrigação x doses de potássio porém os níveis de irrigação exerceram efeitos significativos sobre todas as características de crescimento da planta avaliadas.

Tabela 2. Resumo das análises de variância do experimento para estudo de regressão dos dados das variáveis de crescimento: diâmetro do copa (DC), altura da planta (Ap), diâmetro de caule (Dcau) e número de ramos ( $\mathrm{Nr}$ ), de pinhão-manso submetido aos diferentes tratamentos ao final de 442 DAT (Lavras, 2008)

\begin{tabular}{|c|c|c|c|c|c|}
\hline \multirow[b]{2}{*}{$\begin{array}{l}\text { Fonte de } \\
\text { variação }\end{array}$} & \multirow[b]{2}{*}{ GL } & \multicolumn{4}{|c|}{ Quadrado médio } \\
\hline & & $\begin{array}{l}D C \\
(\mathrm{~cm})\end{array}$ & $\begin{array}{l}\text { Ap } \\
(\mathrm{m})\end{array}$ & $\begin{array}{l}\text { Dcau } \\
(\mathrm{mm})\end{array}$ & $\mathrm{Nr}$ \\
\hline Blocos & 3 & $2816,8^{*}$ & $0,015^{\text {ns }}$ & $43,4^{\mathrm{ns}}$ & $4,6^{\text {ns }}$ \\
\hline Lâminas (L) & 3 & $3357,4^{*}$ & $0,336^{*}$ & $1374,3^{*}$ & $25,2^{*}$ \\
\hline Reg. linear & 1 & $4303,5^{*}$ & $1,005^{*}$ & $3663,4^{*}$ & $50,5^{*}$ \\
\hline Reg. quadrática & 1 & $5289,1^{*}$ & $0,003^{\text {ns }}$ & $444,0^{*}$ & $18,2^{*}$ \\
\hline Reg. cúbica & 1 & $479,4^{\mathrm{ns}}$ & $0,005^{\text {ns }}$ & $15,5^{\mathrm{ns}}$ & $6,9^{\text {ns }}$ \\
\hline Doses de $\mathrm{K}$ & 3 & $557,4^{\text {ns }}$ & $0,015^{\text {ns }}$ & $38,9^{\text {ns }}$ & $13,3^{\text {ns }}$ \\
\hline $\mathrm{L} \times \mathrm{K}$ & 9 & $316,4^{\text {ns }}$ & $0,049^{\text {ns }}$ & $57,4^{\text {ns }}$ & $3,2^{\text {ns }}$ \\
\hline Resíduos & 45 & 376,7 & 0,045 & 46,8 & 5,3 \\
\hline CV(\%) & & 12,8 & 8,4 & 6,9 & 32,1 \\
\hline Lâminas & & \multicolumn{4}{|c|}{ Médias das lâminas (mm) } \\
\hline $\mathrm{L}_{0}$ & & 130,75 & 2,37 & 85,57 & 5,30 \\
\hline $\mathrm{L}_{40}$ & & 161,13 & 2,46 & 98,61 & 7,75 \\
\hline $\mathrm{L}_{80}$ & & 161,12 & 2,58 & 104,12 & 7,66 \\
\hline $\mathrm{L}_{120}$ & & 155,75 & 2,70 & 106,50 & 7,98 \\
\hline
\end{tabular}

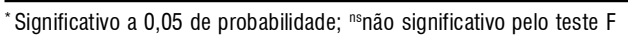

Referente aos tratamentos de adubação, o fato das doses de adubação potássica não terem influenciado os parâmetros de crescimento de plantas de pinhão-manso, pode ter ocorrido devido ao teor inicial de potássio já contido no solo da área experimental, isto é, $101 \mathrm{mg} \mathrm{dm}^{-3}$, uma vez que, segundo Malavolta et al. (1997), este teor é considerado adequado para o desenvolvimento da maioria das culturas. Ressalta-se que, neste trabalho, não se observaram sintomas visuais de deficiência de potássio, como os registrados por Silva et al. (2009) que, ao avaliarem o crescimento e caracterizar os sintomas de deficiências de macro e micronutrientes na cultura do pinhãomanso com omissão de potássio, verificaram que as folhas mais velhas apresentaram clorose marginal, com evolução posterior para necrose.

Na Figura 2A visualiza-se, graficamente, o comportamento do diâmetro de copa da cultura em relação às lâminas de água aplicadas, pela equação de ajuste quadrático, significativa $(\mathrm{P}<$ $0,05)$, estimando-se em $76 \%$ da ECA a lâmina que maximiza essa característica de crescimento da planta. Verifica-se ainda que o diâmetro de copa $(164 \mathrm{~cm})$ estimado com base nessa lâmina foi, em média, 27\% maior que o diâmetro médio das plantas que não receberam irrigação indicando que o pinhão-manso também é exigente em água e pode não se desenvolver satisfatoriamente nas condições climáticas estudada. Esses dados corroboram com os encontrados por Albuquerque et al. (2009) que, analisando o crescimento inicial do pinhão-manso em condições de sequeiro no semiárido nordestino, verificaram um rápido crescimento da cultura no período chuvoso; no entanto, na época seca do ano ocorreu uma drástica redução na sua taxa de crescimento.

Observa-se, na Tabela 2 e na Figura 2B, que a altura de planta apresentou aumento linear com a aplicação dos níveis de irrigação, atingindo altura máxima de 2,70 m quando irrigada com a lâmina de irrigação calculada com base em $120 \%$ da ECA. O comportamento linear observado corrobora com os dados encontrados por Saturnino et al. (2005) ao afirmarem que o pinhão-manso é um arbusto grande e de crescimento rápido, cuja altura normal é de dois a três metros de altura podendo, porém, alcançar até cinco metros em condições especiais como, por exemplo, com o uso da irrigação e adubação corretas. Ressalta-se que o crescimento vigoroso da cultura não é conveniente pois, segundo Laviola \& Dias (2008), pode ocorrer queda de produtividade em razão da demanda de nutrientes pelas partes vegetativas e autossombreamento e, também, dificultar a execução dos tratos culturais e fitossanitários, além das operações de colheita. Os mesmos autores comentam, ainda, que para facilitar a colheita, quando em plantas adultas a altura média das plantas não deve ultrapassar dois metros, o que ocorreu com as plantas irrigadas neste experimento justificando, assim, o uso de técnicas de manejo da cultura como, por exemplo, a poda das plantas.

Referente à análise de regressão do diâmetro de caule em relação às lâminas de irrigação aplicadas, verificou-se que o modelo polinomial quadrático foi o que melhor se ajustou (Figura 2C). Pela equação ajustada o diâmetro de caule máximo foi, em média, de 111,4 mm para uma lâmina de irrigação de 106 $\mathrm{mm}$, o que corresponde a um aumento de $29 \%$ dessa característica de crescimento da cultura em relação às plantas que não receberam irrigação.

O número de ramificações no ramo principal mostrou comportamento quadrático (Figura 2D) em relação às lâminas de irrigação aplicadas, a partir de 442 DAT. Com base na equação ajustada verifica-se que o número máximo de ramificações $(8,1)$ é alcançado com a lâmina de irrigação calculada com base em $90 \%$ da ECA enquanto o número médio de ramificações observado nas plantas que não receberam irrigação foi de 5,30. Este fato reforça a importância do uso da irrigação na região de Lavras com vista à obtenção de melhores 
A.
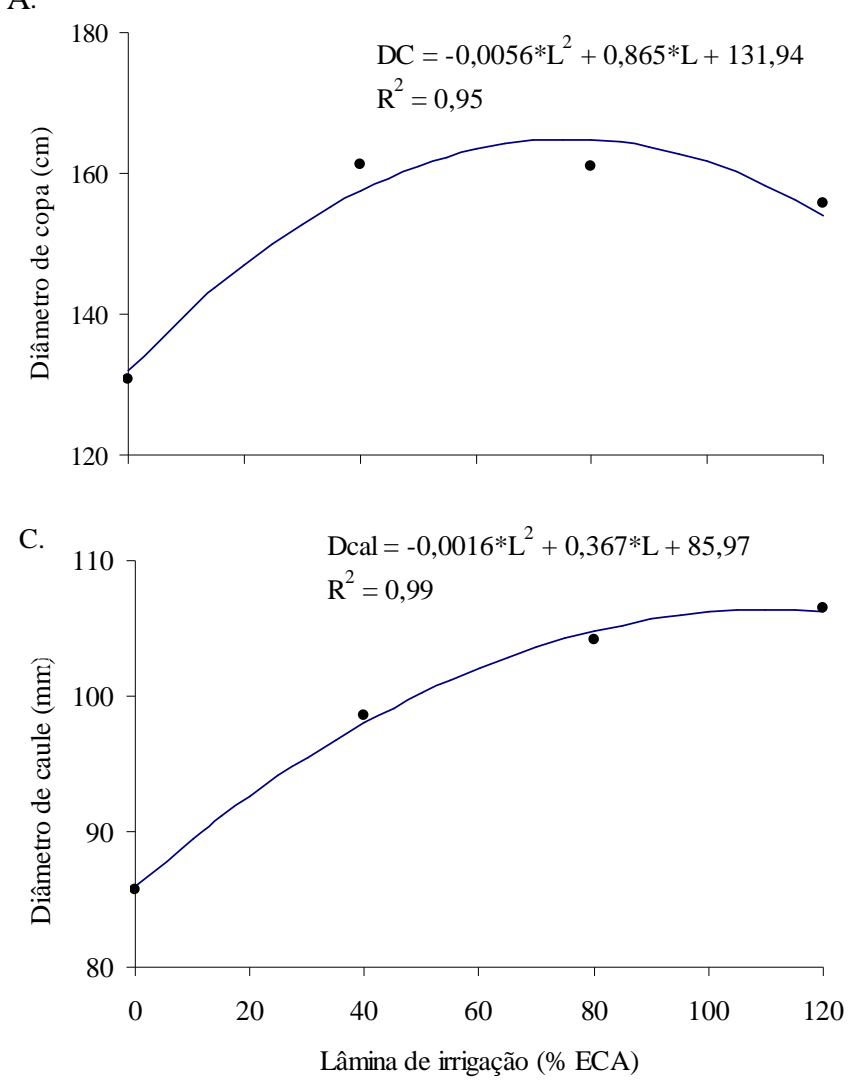

B.
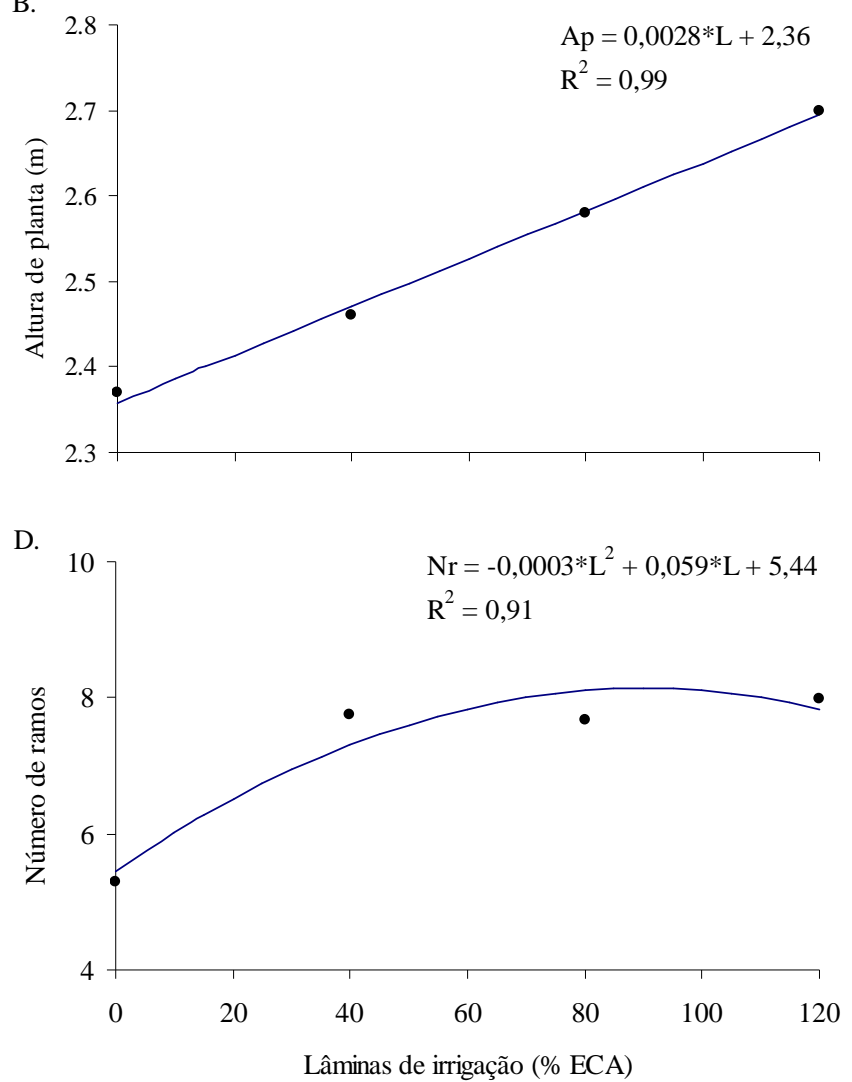

Figura 2. A. Diâmetro de copa B. Altura de planta C. Diâmetro de caule D. Número de ramos de pinhão-manso em função das lâminas de irrigação aplicadas

condições de desenvolvimento e produção do pinhão-manso de vez que, segundo Anez et al. (2005), quanto maior for o número de ramificações na planta maior será, possivelmente, sua produtividade, visto que a primeira inflorescência do pinhão-manso é apical e assim que surge força o brotamento de dois novos ramos secundários, que passam a ser axilares até o surgimento de novas inflorescências que, por sua vez, impedem novamente o crescimento apical surgindo dois novos ramos terciários.

A análise estatística também revelou que não houve efeito significativo da adubação potássica sobre a produtividade de sementes de pinhão-manso; entretanto, as diferentes lâminas de irrigação influenciaram este fator de produção. Finalmente, observou-se ainda que a interação entre as diferentes doses de potássio e os níveis de irrigação aplicados não influenciou estatisticamente os valores de produtividade de sementes do pinhão-manso (Tabela 3).

Estatisticamente, constatou-se que a equação quadrática também foi a que melhor se ajustou aos dados de produtividade de sementes de plantas irrigadas com as diferentes lâminas de irrigação (Figura 3), motivo pelo qual nesta equação a produtividade máxima (192 $\left.\mathrm{kg} \mathrm{ha}^{-1}\right)$ é alcançada irrigando a cultura com a lâmina calculada com base em $120 \%$ da ECA. Observa-se, portanto, que a produtividade das plantas irrigadas com essa lâmina foi, em média, $69 \%$ maior quando comparada com a das plantas que não receberam irrigação. Ressalta-se que, apesar da produtividade das plantas irrigadas ter superado as de sequeiro, os valores de produtividade foram relativamente
Tabela 3. Resumo das análises de variância do experimento para estudo de regressão dos dados das variáveis de produtividade de sementes de pinhão-manso submetido aos diferentes tratamentos ao final de 442 DAT (Lavras, 2008)

\begin{tabular}{|c|c|c|c|}
\hline \multirow{2}{*}{\multicolumn{2}{|c|}{$\begin{array}{l}\text { Fonte de } \\
\text { variação }\end{array}$}} & \multirow{2}{*}{ GL } & Quadrado médio \\
\hline & & & Produtividade $\left(\mathrm{kg} \mathrm{ha}^{-1}\right)$ \\
\hline Blocos & & 3 & $1777,13^{\text {ns }}$ \\
\hline Lâminas & & 3 & $19984,94^{*}$ \\
\hline Regressã & ão linear & 1 & $55111,09^{*}$ \\
\hline Regressã & ão quadrática & 1 & $48041,20^{*}$ \\
\hline Regressã & ão cúbica & 1 & $2,55^{\mathrm{ns}}$ \\
\hline Doses de & & 3 & $14978,95^{\text {ns }}$ \\
\hline LxK & & 9 & $5270,49^{\text {ns }}$ \\
\hline Resíduos & & 45 & 6149,34 \\
\hline CV(\%) & & & 48,60 \\
\hline Lâminas & & & Médias das lâminas (mm) \\
\hline $\mathrm{L}_{0}$ & & & 113,18 \\
\hline $\mathrm{L}_{40}$ & & & 157,18 \\
\hline $\mathrm{L}_{80}$ & & & 182,89 \\
\hline $\mathrm{L}_{120}$ & & & 192,10 \\
\hline
\end{tabular}

inferiores aos alcançados por Purcino \& Drummond (1986) ao observarem que o pinhão-manso começou a produzir logo no segundo ano, atingindo $2000 \mathrm{~kg} \mathrm{ha}^{-1}$ de sementes e Drumond et al. (2007) que obtiveram produtividades variando de 330 $\mathrm{kg} \mathrm{ha}^{-1}$, em condições de sequeiro, a $1200 \mathrm{~kg} \mathrm{ha}^{-1}$, em área irrigada, já no primeiro ano de cultivo em Petrolina, PE. Ressaltase que o clima da região sul do estado de Minas Gerais difere 


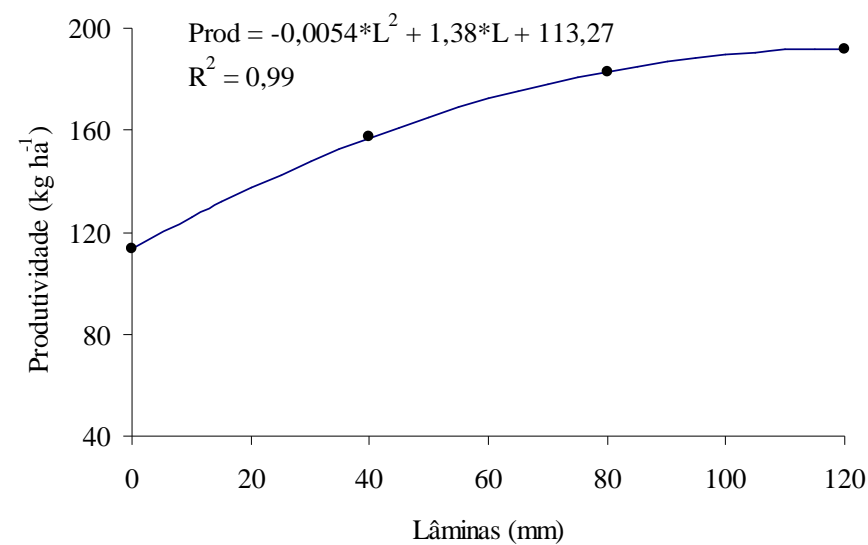

Figura 3. Produtividade de sementes de pinhão-manso em função das lâminas de irrigação aplicadas

do da região nordestina brasileira, o que pode justificar os baixos valores de produtividade de sementes de pinhão-manso obtidos neste trabalho.

\section{ConclusõEs}

1. A adubação potássica não afetou os parâmetros de crescimento e produtividade de sementes do pinhão-manso irrigado na região Sul de Minas Gerais.

2. Os níveis de irrigação produziram efeitos significativos sobre a produtividade do pinhão-manso.

\section{AgradeCimentos}

À Fundação de Amparo à Pesquisa do Estado de Minas Gerais, pelo apoio financeiro, e à Universidade Federal de Lavras (UFLA), pela infraestrutura necessária à realização do experimento.

\section{LITERATURA CITADA}

Albuquerque, F. A.; Arriel, N. H. C.; Beltrão, N. E. de M.; Lucena, A. M. A.; Souza, S. L.; Freire, M. A. O.; Sampaio, L. R. Análise de crescimento inicial do Jatropha curcas em condições de sequeiro. Revista Brasileira de Oleaginosas e Fibrosas, v.13, p.99-106, 2009.

Amorim, D. A.; Favero, A. C.; Regina, M. A. Produção extemporânea da videira, cultivar Syrah, nas condições do sul de Minas Gerais. Revista Brasileira de Fruticultura, v.27, p.327-331, 2005.

Anez, L. M. M.; Coelho, M. F. B.; Albuquerque, M. C. F.; Dombroski, J. L. D. Caracterização morfológica dos frutos, das sementes e do desenvolvimento das plântulas de Jatropha elliptica. Revista Brasileira de Botânica, v.28, p.563-568, 2005.

Arruda, F. P.; Beltrão, N. E. de M.; Andrade, A. P.; Pereira, W. E.; Severino, L. S. Cultivo de pinhão-manso (Jatropha curcas L.) como alternativa para o semiárido nordestino. Revista Brasileira de Oleaginosas e Fibrosas, v.8, p.789-799, 2004.
Brasil. Ministério de Minas e Energia. Boletim mensal dos combustíveis renováveis, n.20, 2009. <http:// www.mme.gov.br>. 15 Abr. 2010.

Carnielli, F. O combustível do futuro. Boletim Informativo, Belo Horizonte, v.29, n.1413, 2003. <http:// www.ufmg.br/boletim/ bol1413/quarta.shtml>. 15 Abr. 2010.

Custódio, A. A. P.; Gomes, N. M.; Lima, L. A. Efeito da irrigação sobre a classificação do café. Engenharia Agrícola, v.27, p.691-701, 2007.

Dabdoub, M. J.; Bronzel, J. L.; Rampin, M. A. Biodiesel: visão crítica do status atual e perspectivas na academia e na indústria. Química Nova, v.32, p.776-792, 2009.

Dantas, A. A. A.; Carvalho, L. G.; Ferreira, E. Classificação e tendências climáticas em Lavras, MG. Ciência e Agrotecnologia, v.31, p.1862-1866, 2007.

Drumond, M. A.; Anjos, J. B.; Paiva, L. E.; Morgado, L. B.; Reis, E. M. Produção de pinhão-manso no Semiárido Brasileiro. In: Congresso Internacional de Agroenergia e Biocombustíveis, 1, 2007, Teresina. Anais... Teresina: Embrapa Meio Norte, 2007. CD-Rom

Jiang M.; Zhang J. Water stress-induced abscises acid accumulation triggers the increased generation of reactive oxygen species and up-regulates the activities of antioxidant enzymes in maize leaves. Journal of Experimental Botany, v.53, p.2401-2410, 2002.

Lange, A.; Martines, A. M.; Silva, M. A. C.; Sorreano, M. C. M.; Cabral, C. P.; Malavolta, E. Efeito de deficiência de micronutrientes no estado nutricional da mamoneira cultivar Íris. Pesquisa Agropecuária Brasileira, v.40, p.61-67, 2005.

Laviola, B. G.; Dias, L. A. S. Teor e acúmulo de nutrientes em folhas e frutos de pinhão-manso. Revista Brasileira de Ciência do Solo, v.32, p.1969-1975, 2008.

Laviola, B. G.; Martinez, H. E. P.; Souza, R. B.; Alvarez V.; V. H. Dinâmica de $\mathrm{N}$ e $\mathrm{K}$ em folhas, flores e frutos de cafeeiro arábico em três níveis de adubação. Bioscience Journal, v.22, p.33-47, 2007.

Malavolta, E.; Vitti, G. C.; Oliveira, S. Avaliação do estado nutricional das plantas: princípios e aplicações. 2.ed. Piracicaba: Potafós, 1997.319p.

Prezotti, L. C. Fertilização do cafeeiro. In: Zambolim, L. Tecnologias de produção de café com qualidade. Viçosa: UFV, 2001. p.607-615.

Purcino, A. A.; Drummond, O. A. Pinhão-manso. Belo Horizonte: EPAMIG, 1986. 7p.

Sato, F. A.; Silva, A. M.; Coelho, G.; Silva, A. C.; Carvalho, L. G. Coeficiente de cultura (kc) do cafeeiro (Coffea arabica L.) no período de outono-inverno na região de Lavras - MG. Engenharia Agrícola, v.27, p.691-701, 2007.

Saturnino, H. M.; Pacheco, D. D.; Kakida, J.; Tominaga, N.; Gonçalves, N. P. Cultura do pinhão-manso (Jatropha curcas L.). Informe Agropecuário, v.26, p.44-78, 2005.

Silva, A. C.; Silva, A. M.; Coelho, G.; Rezende, F. C.; Sato, F. A. Produtividade e potencial hídrico foliar do cafeeiro Catuaí, em função da época de irrigação. Revista Brasileira de Engenharia Agrícola e Ambiental, v.12, p.21-25, 2008.

Silva, E. B.; Tanure, L. P. P.; Santos, S. R.; Resende Júnior, P. S. Sintomas visuais de deficiências nutricionais em pinhãomanso. Pesquisa Agropecuária Brasileira, v.44, p.392-397, 2009. 